\title{
MICROSTRUCTURAL BEHAVIOUR OF A SUPERALLOY UNDER REPEATED OR ALTERNATE LC.F. AT HIGH TEMPERATURE
}

\author{
Valérie Brien* \# Brigitte Décamps ** and Allan J. Morton** \\ - Laboratoire d'Etudes des Microstructures, UMR CNRS-ONERA 104, BP 72, 92322 Châtillon Cedex, France \\ * Now at Department of Materials, Imperial College, Prince Consort Road, London SW 728 , UK \\ *. Laboratoire de Métallurgie Structurale, URA CNRS 1107. Université Paris-Sud, Baitiment 413, 91405 Orsay Cedex, France \\ ... CSIRO, Division of Material Science and Technology, Private bag 33, Rosebank MDC, Clayton, Victoria, Australia 3169
}

\section{Abstract}

Total strain controlled Low Cycle Fatigue tests have been performed at $950^{\circ} \mathrm{C}(1223 \mathrm{~K})$ on the AMI superalloy and its microstructural behaviour has been studied by Transmission Electron Microscopy. The mechanisms of deformation have been studied mainly on repeated fatigue $R_{1}=0$ but also in alternate one $\left(R_{2}=-1\right)$ along the cubic [CO1] axis. In simple tension localisation of dislocations networks at the matrix/precipitate interface perpendicular to the $<001>$ loading axis occurs. These dislocations are shown to always relax the misfit. In fatigue tests, the larger the total strain imposed is or the greater the number of cycles is, the more the deformation spreads out to the vertical channels, In small total strain, type $\mathrm{N}$ coarsening is observed as early as 200 cycles. For $\mathrm{R}=-1$, compression is shown to deform the vertical channels without formation of networks. Alternate fatigue leads to type $\mathrm{N}$ coarsening for very few cycles.

\section{Introduction}

Industrial gas turbines blades in use undergo very complicated mixed effects of croep, fatigue and environment. The work presented here concems mechanical fatigue which occurs more especially in the base of these blades when transitions between either normal runnings or idling of the engine occur. In fact, the fatigue experienced is of thermomechanical type ; but to get basic information, a test temperature of $950^{\circ} \mathrm{C}(1223 \mathrm{~K})$ was chosen. As the initiation and growth of cracks in fatigue has becr the object of a certain amount of studies in the past, and as the knowledge of the behaviour of nickel based superalloys under fatigue before any cracks appears is rather limited ; the aim of this work was concentrated on the mechanisms of deformation during the damaging stage which is also extremely important since localisation of plastic deformation can condition the further stages. The type of fatigue tests and experimental conditions were chosen as close as possible to real conditions of the material in use: plastic low cycle fatigue, total strain imposed tests, temperature $\mathrm{T}=1223 \mathrm{~K}\left(950^{\circ} \mathrm{C}\right)$, frequency $\mathrm{f}=0.25 \mathrm{~Hz}$, loading along the turbine blades main axis 1 [001]. Indeed, most studies indexed in literature (cf. References 1 to 12) concern $R_{\mathcal{E}}=-1$ fatigue ( $R_{\mathcal{Q}}$ is the ratio of the minimum strain to the maximum strain for each cycle). So, although most of our tests have been done at $R_{\varepsilon}=0$, some tests with $R_{E}=-1$ have been performed in order to make comparisons and see the influence of a reversed loading.

Another part of the present work (already published : Décamps, Brien and Morton 1992, Reference 13) compared microstructures after strain-controlled fatigue tests and stress-controlled fatigue tests (same level of initial stress).

\section{Experimental and Method}

Mechanical tests have been performed using a tension hydraulic INSTRON machines on samples cut in AM1 superalloy provided by SNECMA (Table I gives the nominal composition of the alloy). Figure 1 presents the metallographic structure of the AMl alloy. Is is pointed out that the two phases composing the alloy are coherent despite a misfit of $\delta=-10^{-3}$ at the temperature of our fatigue tests (Royer 1995, Reference 14). Tests were carried out at $950^{\circ} \mathrm{C}(1223 \mathrm{~K})$ at $0.25 \mathrm{~Hz}$ in air along the crystallographic axis [001]. For $R_{\varepsilon}=0$ tests, the range of $\Delta \varepsilon^{t}$ was $0.6-2.2 \%$, the number of cycles varied from 1 to $2.10^{4}$. Some of the tests were continued to rupture.

Table I : Percentage composition in weight of the AM1 superalloy

\begin{tabular}{|c|c|c|c|c|c|c|c|}
\hline $\mathrm{Ni}$ & $\mathrm{Co}$ & $\mathrm{Cr}$ & $\mathrm{Al}$ & $\mathrm{W}$ & $\mathrm{Ta}$ & $\mathrm{Mo}$ & $\mathrm{Ti}$ \\
\hline Base & 6.5 & 7.5 & 5.3 & 5.5 & 8 & 2 & 1.2 \\
\hline
\end{tabular}

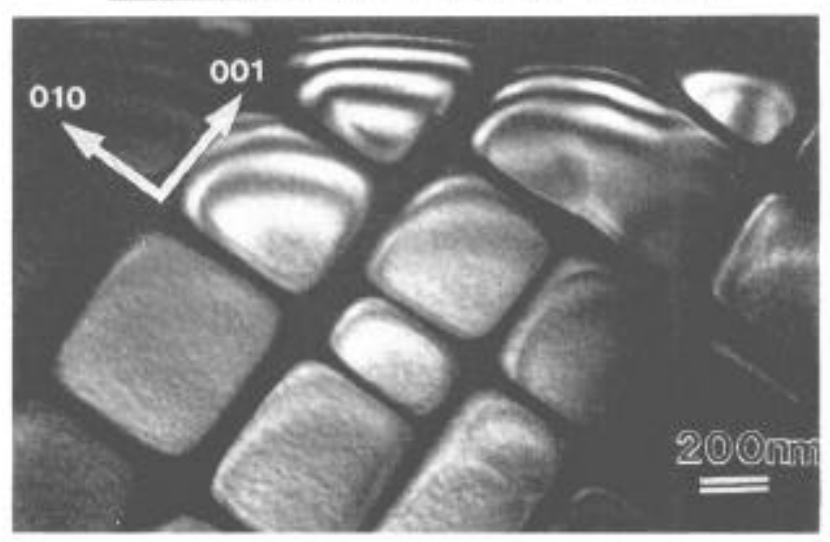

Figure 1: Metallographic structure of the AM1 alloy

The $\gamma$ precipitates are cuboids aligned along the cubic crystallographic directions and represent $65 \%$ of the total volume at $950^{\circ} \mathrm{C}$.

The present work has been mainly concentrated on the $R_{\boldsymbol{C}}=0$ fatigue and on exploration of the influence of the amplitude $\Delta \varepsilon^{t}$ and of the number of cycles $\mathrm{N}$ on the structural mechanisms of deformation. Also, a compression test and two $R_{e-1} 1$ fatigue tests have been carried out. The tables II and III (cf. end of article) index the mechanical details of the different tests carried out in this study. The compression test was performed at the same level of stress as the tension one done at $\Delta E^{t}=1.6 \%$ in tension.

All observations of microstructures were made by Transmission Electron Microscopy either on a JEOL. 2000 EX, a JEOL $200 \mathrm{CX}$ or a PHILIPS CM20. Thin foils were thinned down first mechanically then by the classic two jets electrochemical method using a $90 \%$ acetic acid, $10 \%$ perchloric acid solution. Foils were fully orientated in order to follow the projection of the loading axis 10011, noted $p$ on the micrographs. 


\section{Results}

\section{$R_{x}=0$ fatigue}

For $\mathrm{N}=1, \Delta \varepsilon^{t}=1.25 \%$ the microstructure of deformation (that corresponds to a simple tension test) is very anisotropic. The anisotropy is characterised by a preferred localisation of the dislocations in the channels perpendicular to the [001] axis (d. figure 2) : $\gamma / \gamma(001)$ interfaces are covered by polygonal networks of dislocations.
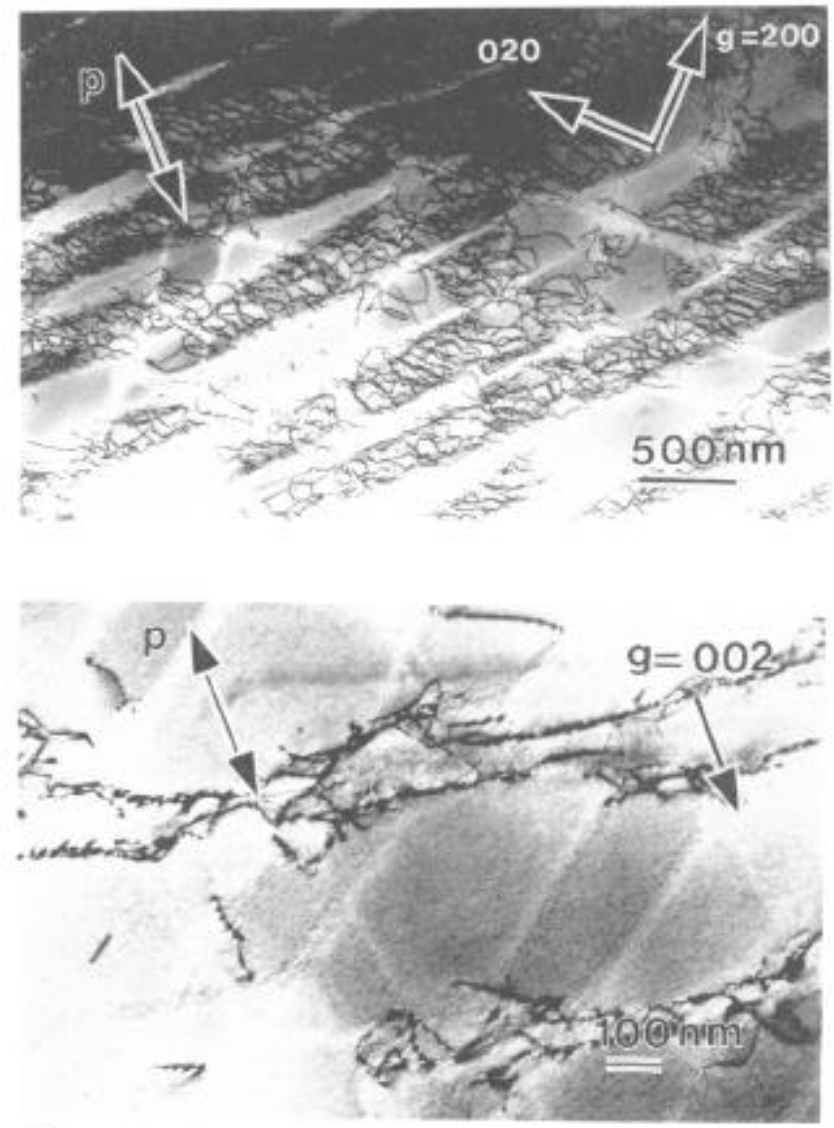

$2 b$

Figure 2: Zone $A$ microstructure, $\mathrm{N}=1, \Delta e^{t}=1.25 \%$. One can notice the preferential activation of the channels perpendicular to [001] in comparison to the two other channels. Foil cut perpendicular to [111]. a/ Zone axis $=\{001] . \mathrm{b} /$ Zone axis between $[110]$ and $[010]$.

A careful study has been achieved in order to get the localisation of the extra plane associated to the either edge or $60^{\circ}$ mixed dislocation localised at the $\gamma \gamma$ interfaces.

This study requires the full orientation of the dislocations, the sign of the Burgers vector and the relative positions of the two phases. To get the first information, Bright field images with g.b-2 for each dislocation have been taken in order to get the asymmetrical contrast (Hirsh, Howie, Nicholson, Pashley and Whelan 1965 - Reference 15). $\mathrm{PS} / \mathrm{RH}$ convention has becn used (Bilby, Bullough and Smith 1955 . Reference 16) and Burgers vectors are determined by the classic extinction criterion (Howie and Whelan 1962 - Reference 17). The second information is obtained using stereomicroscopy. This study showy that all dislocations localised at the interfaces present an extra plane in the precipitates. So, they are on the right side of the interface to relax the existing misfit between $\gamma$ and $\gamma$. Dislocations at the interface form polygonal networks generally with 6 sides : they are classic honeycombs found in fec materials; interfacial networks of this type are encountered after creep of the same type of superalloys (Fredholm 1986 - Reference 18). Figure 3 present an exemple of such a relaxing network.
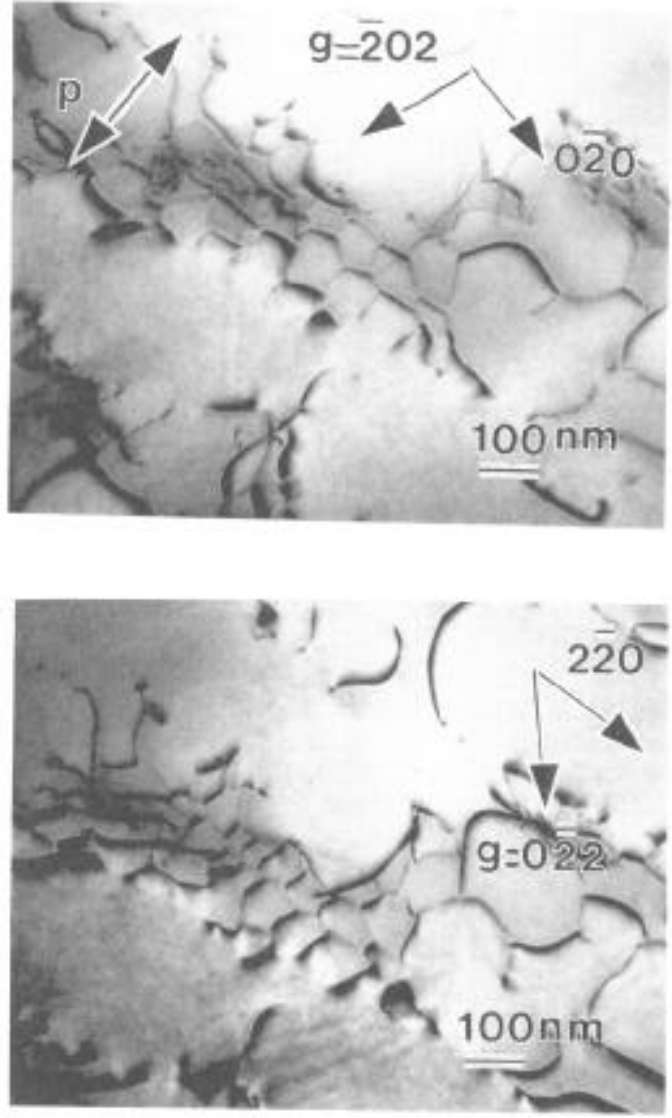

3b

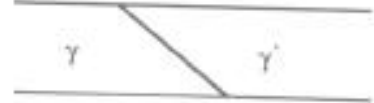

Figure 3 : Network relaxing the interfacial misfit. $\Delta x^{t}=1.5 \%, N=25$. Arrows indicate the double asymmetrical contrast. Foil parallel to [111], a/ Zone axis =[101], b/ Zone axis =|1111, $\mathrm{d}$ Schema showing the relative position of the two phases : cut seen from the left of photos.

When the number of cydes increases, an expansion of the deformation to the vertical channels is noted. However, the resulting microstructure still presents a strong partition of the plastic deformation regarding the horizontal and vertical channels with an obvious preference for horizontal ones (cf. figure 4). This homogeneity is noted as well if is very big, the bigger is, the sooner the homogeneisation is observed (smaller $\mathrm{N}$ ).

On the contrary, if the number of cycles $\mathrm{N}$ increases again. anisotropy is no longer observed : the microstructure of deformation is then completely homogeneous (ci. figure 5)

All the dislocations, either from ore interface or the other have been shown to relax the misfit, except for large number of cycles, where some of the dislocations presented the other sign.

So, the deformation microstructures in many foils from each fatigue test from this map have been observed and two major domains were found ( $\mathrm{f}$. map in figure 6 ). The first called $\mathrm{H}$ is a domain where the deformation microstructure is homogeneous, the socond is a 
domain, called A, gives rise to anisotropic deformation microstructure, This anisotropy is cither micromechanical, or comes from the morphology of the precipitates (coarsening). Indeed, for smaller $\Delta \varepsilon^{t}$ (like $0.6 \%$ ) the dislocations never extend to the secondary channels and the microstructure always stays anisotropic. Moreover, for large number of cycles, $\mathrm{N}>200$, this micromechanical anisotropy results in oniented carsening of type $\mathrm{N}$ (classical notation to describe coarsening perpendicular to the stress axis), i.e, exactly like in tension creep (cf. figure 7).

So, the anisotropy of the deformation microstructure is enhanced by small values of $\Delta E^{t}$, whereas large values of $\mathrm{N}$ increase the tendancy for homogeneous microstructures (except for small $\Delta E^{t}$ ). These two rules and the localisation of the two domains are summarised in the previous map. The type $\mathrm{N}$ coarsening domain is noted as well, and the greater intensity of shadowing of the domain reflects the stronget tendancy for coarsening

Very rarely, shearing (except for big $\Delta e^{t}$ like $2.2 \%$ i.e. for big stresses) has been noted in microstructures, and all interfacial dislocations generally relax the $\gamma / \gamma$ misfit.

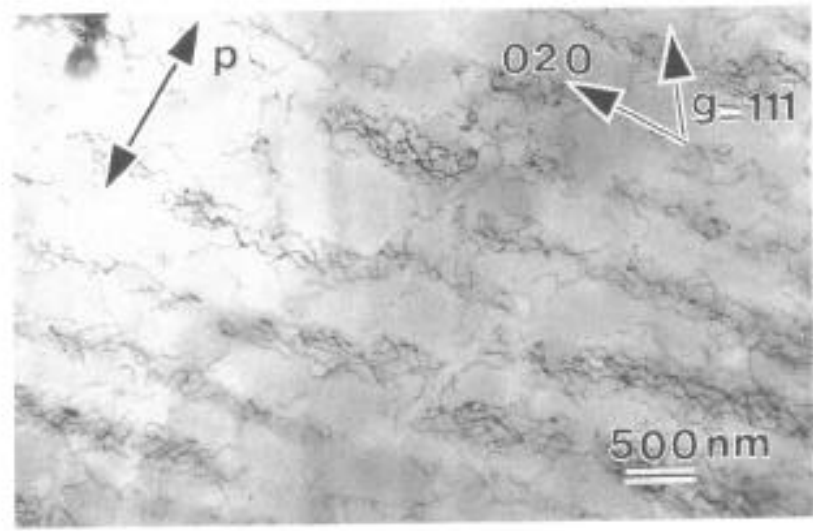

Figure 4: Zone A microstructure. $\Delta e^{t}=1.5 \%, N=25$. Foil parallel to [111]. Zone axis=|1011. deformation is localised essentially in channels perpendicular to the loading axis, forming networks at interfaces.

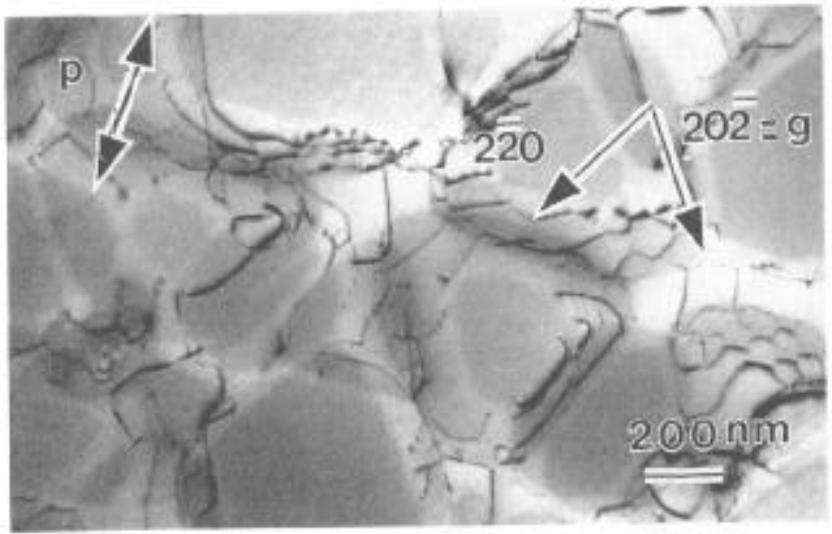

Figure 5: Zone $\mathrm{H}$ microstructure: the $3 \gamma$ channels exhibit an equivalent density of dislocations. $N=1300, \Delta \varepsilon^{t}=1.28 \%$. Fotl cut perpendicular to [111]. Zone axis = [111]

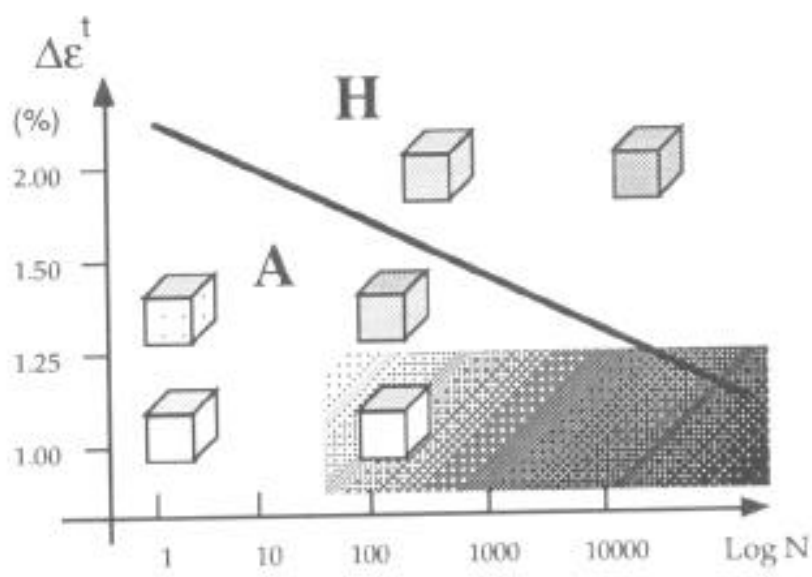

Cubic procipitate: the intensity of the coloration of the faces
embodies the level of deformation localised at this interface

FF⿱ Ty: 9 Tye N Coarsening domain (the darker is the region the more intense is the coarsening

Figure 6: Map of microstructures of deformation in $R_{\ell}=0$ fatigue versus $\Delta E^{t}$ and $N$. This map is found to be divided in two main zones : zone A where the microstructures of deformation are anisotropic and zore $\mathrm{H}$ where the microstructures of deformation are homogeneous

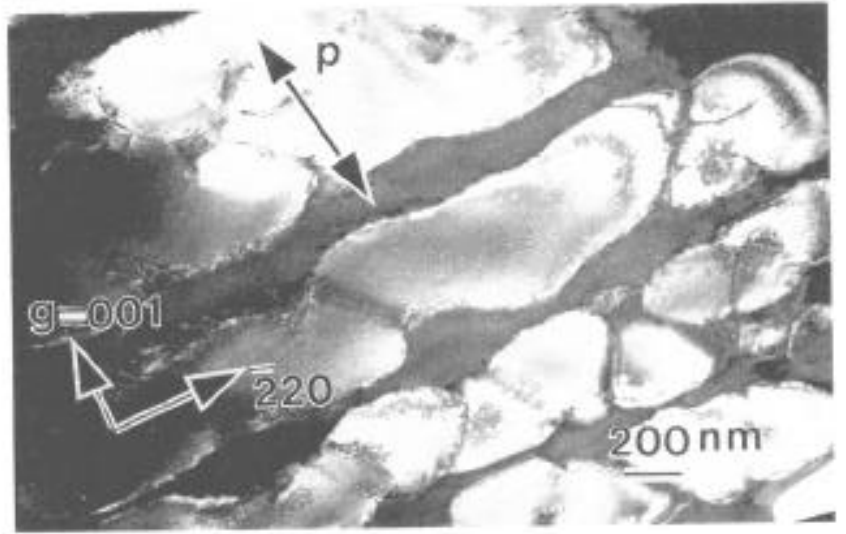

Figure 7 ; Zone A microstructure. $N=200, \Delta e^{t}=0.63 \%$. Type $N$ oriented coarsening of the $A M 1$ alloy under $R_{E}=0$ LCF for a great number of cycles at small $\Delta E^{t}$. Foil cut perpendicular to [111]. Zone axis $=[112]$.

\section{$R_{x}=0$ fatigue discussion}

To explain the present observation we need to consider the presence, evolution and distribution of internal stresses within the fatigued specimen.

The first one comes from the misfit between the $\gamma$ phase and the $\gamma$ phase. This misfit $\delta=\left(a_{-} a^{\prime}\right) / 2 a$ is equal to $-10^{-3}$ at $950^{\circ} \mathrm{C}$, and gives rise to compression (tension) stresses in the $\gamma(\gamma)$ phase a $\left(a^{\prime}\right)$ is the $\gamma(\gamma)$ phase parameter. These compression stresses are at the origin of the partition of the plastic deformation since the resulting local streses in horizontal channels and in vertical ones are different.

Tritely, the resulting stresses in the vertical channels are weaker than in horizontal ores since the applied and the misfit stresses are of opposite signs. This results in the localisation of the deformation in the horizontal channels.

This preferential localisation of deformation noted also by Benyoucef (1994 - Reference 19) after tension can be explained by the existence of the misfit. This argument had already been put forward by this writer. 
After a while, since deformation occurs only in these channels, and since they have such a Burgers vector that they reduce the misfit, misfit stresses will be very low in horizontal channels. That phenomena destroying the source of the partition, added to the natural hardening due to the presence of dislocations themselves induces the extension of deformation to the vertical channels. This expansion is assisted at high stresses by shearing of $\gamma$ precipitates.

A calculation of the number of pure edge dislocations nexded to fully reduce the misfit at one interface can be done via the Brooks formula.

$$
\frac{\sqrt{2} \mathrm{~d}_{\gamma} \cdot 8}{|\mathrm{~b}|}=\frac{\sqrt{2}(400 \text { to } 500) \cdot 10^{-3}}{\frac{\sqrt{2}}{2}, 3,58 \cdot 10^{-1}}=2 \text { to } 3 \text { dislocations }
$$

where

\section{$\mathrm{d}=$ length of the $\gamma$ precipitates $=400$ to $500 \mathrm{~nm}$}

$\delta=$ absolute value of the misfit between the two phases $=10^{-3}$

$b=$ Burgers vector of the considered dislocation : $a / 2|110|$

$\mathrm{a}=$ cubic lattice parameter of $\gamma$ phase

So it means that in $R_{E}=0$ fatigue after a small number of cycles, the misfit stresses are relaxed, only in the channels perpendicular to [001]. since only $(001)$ interfaces are concerned by the location of dislocations.

One has to take into account a second type of stresses : a stress coming from the strongly composite structure of such a superalloy. We make use of the plasticity composite model of Mughrabi (1979 Reference 20) used for inhomogenecus distribution of plastic deformation adopted by monophase metals after fatigue loadings. This idea has also been exploited for nickel base superalloys by different authors (Kuhn 1991-Mughrabi 1992-Véron 1995 - References 21 to 23).

The model has been considered here in the vertical direction (the horizontal effect has been neglected). One can show (to be published by Brien et al.) that these stresses called compatibility stresses find their existence in the presence of plastic deformation in vertical channels. Our calculation gives estimate of these stresses : they are found to equal $80 \%$ of $\left(\sigma_{a}-\sigma_{0}\right)$ where $\sigma_{0}$ is the elasticity limit of $\gamma$ phase inside the superalloy (including Orowan stresses, stress coming from misfit and hardening stress coming from the solid solution) and $\sigma_{a}$ is the applied stress. So, this type of stress doesn't exist in the beginning of the fatigue, but as soon as deformation ocrurs in vertical channels. compatibility stresses arise in vertical channels and delay them to deform. These scoond stresses assist the anisotropic partition of the plastic deformation.

Explanations of the type of coarsening observed can be explained by a recent coarsening model developed by Véron (Reference 23) for superalloys deformed under creep conditions. This model is based on the exastence of gradients of elastic encrgy between the interfaces provoked by the anisotropic relaxation of the misfit stresses by dislocations.

These elastic energy gradients are of the same type as those observed by Veron after tension creep : $\{001\}$ interfaces are relaxed as $1010\}$ and $(100)$ enes are not. Moreover the fact that at levels of stresses where the anisotropic micromechanical feature disappears rather early, no oriented coarsening is proves that the micromechanical anisotropy is really the needed condition for the type $\mathrm{N}$ oriented coarsening in repeated fatigue.

It is also worth noting that some of $R_{E}=0$ tests exhibit bands of deformation, but that phenomena will be discussed separetely,

\section{$R_{x}=-1$ fatigue} fatigue.

The superalloy presents a peculiar microstructure after the $R_{E}=-1$

After one cycle fone tension followed by one compression), as well as deformation localized in interfaces perpendicular to [001] due to one simple tension, the deformation localizes in channels parallel to [001] (ct. figure 8). The dislocations observed in these vertical channels belong to only one slip system : here $1 / 2<-101>\{1-11\}$, as a consequence can not form networks, and they are also founf to be of the correct sign to relax the misfit between $\gamma$ and $\gamma^{\prime}$. A compression test has been order to confirm that the new observation comes directly from the compression (and not from mixed effects of a compression following a tension). This compression test presents a microstructure where only the channels parallel to [001] are affected by deformation : the dislocation found in each channel belong to only one slip system.

After cycling, here 113 cycles, the precipitates are coarsened in plates perpendicular to the loading axis. So, $R_{\varepsilon^{m-1}}$ fatigue producs very fast type $\mathrm{N}$ coarsening (cf. figure 9),

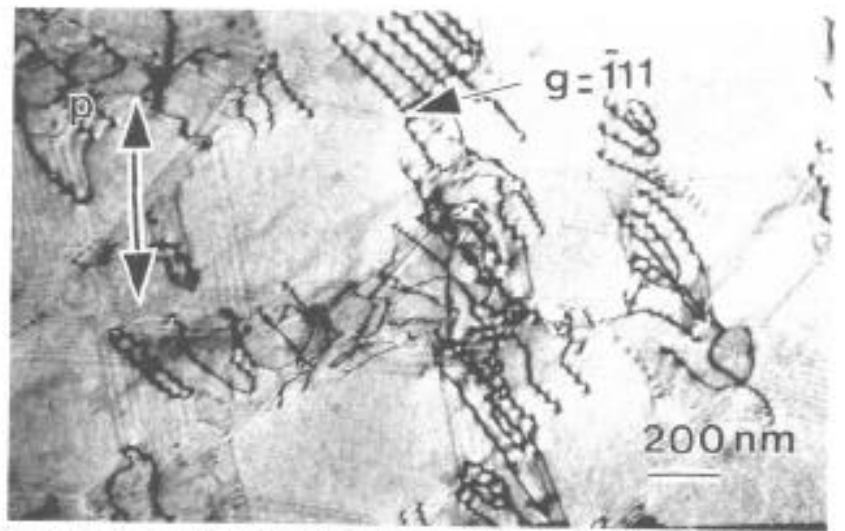

Figure $8: R_{\varepsilon}=-1$ fatigue microstructure after 1 cycle. $N=1, \Delta e^{t}=2 \times 1.25 \%$. Localisation of deformation in the channels containing the [001] axis as well as in the perpendicular one is observed. Foil cut perpendicular to [111]. Zone axis $=[101]$.

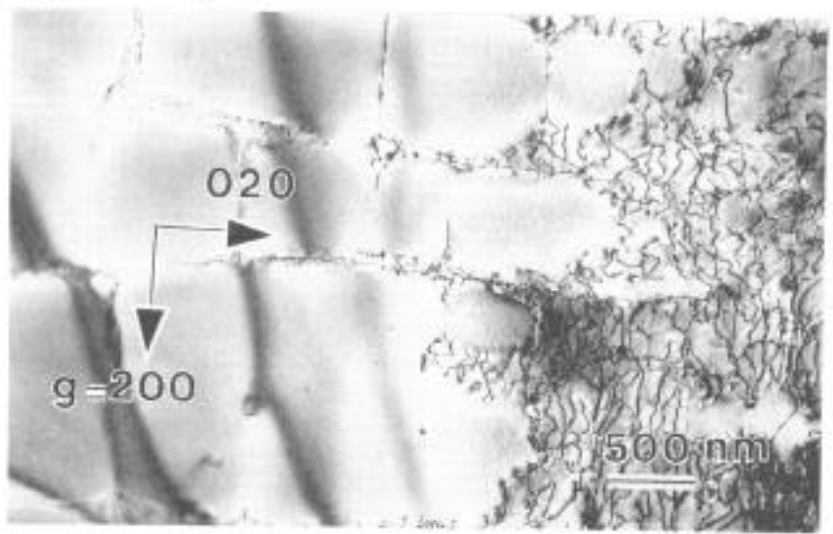

Figure 9: $R_{e}=-1$ fatigue microstructure after cycling 113 cycles. $N=113$, $\Delta \varepsilon^{t}=2 \times 1.25 \%$. All foils exhibit type $\mathrm{N}$ coarsening. Foil cut perpendicular to $[001]$. Zone axis $=[001]$.

\section{$R_{E}=-1$ fatigne discussion}

The localisation of the deformation in vertical channels can be explained on the base of exactly the same arguments put forward for $R_{\mathcal{E}}=0$ fatigue behaviour. Indeed the internal misfit stresses in vertical channels added to the applied stress result in a much higher local stress in vertical channels than in horizontal ones.

A major difference between $R_{\mathrm{R}}=0$ and $R_{\mathrm{E}}=-1$ fatigue is the much higher efficiency of diffusion effects in alternate fatigue. Coarsening is observed much earlier for $R_{\varepsilon}=-1$ fatigue ; only 113 cycles; the type of coarsening is of $\mathrm{N}$ type : exactly the same type as in repeated fatigue or in tension creep. 50 , alternate fatigue has a very strong effect on diffusion. Explanations of the type of fatigue observed can be explained by the coarsening model already mentionned. Two hypothesis coming from experiments observations are made : 1/ Simple tension (compression) localises the deformation only in horizontal (vertical) channels; 2 / For each cycle, the previous phenomena applies and that the plastic deformation has the same absolute value for tension and compression. So, it means that twice as much volume of $\gamma$ phase 
is affected by deformation in compression than in tension, and after $\mathrm{N}$ cycles in alternate fatigue one horizontal channel contains globally twice as much deformation as a vertical channel. Moreover, as all the dislocations studied are found to relax the misfit : it means that the misfit in the horizontal channels will be reduced twice as quickly as that in the vertical channels : the elastic energy gradients then observed are of exactly the same type than in $R_{\varepsilon}=0$ fatigue.

So, on the base of rather rough but reasonable hypothesis and reasoning, it is possible to explain the type $N$ coarsening observed in alternate fatigue.

\section{Conclusion}

- A map of microstructures of deformation has been established in $R_{\varepsilon}=0$ fatigue versus the number of cycles $N$ and the total strain for the fatigue ; different zones are pointed out on this map : an homogeneous $\mathrm{H}$ domain, an anisotropic A domain as well as a coarsening domain. These domains are accounted for on the base of the influence of internal stresses like misfit stresses and compatibility stresses coming from the strong composite structure of the superalloy. The interpretation of this map leads us to structural mechanisms of deformation which rule $R_{\mathcal{E}}=0$ fatigue deformation.

- The behaviour of the AM1 superalloy is very different in $R_{\varepsilon}=0$ fatigue and in $R_{\mathbf{e}}=-1$ fatigue. We point out theses differences and try to explain them

- It is shown that alternate strain-controlled fatigue $\left(R_{\mathcal{E}}=-1\right)$ at $950^{\circ} \mathrm{C}(1223 \mathrm{~K})$ leads very quickly to a rafted structure perpendicular to the loading axis [001] (less than an half an hour) and that the type of coarsening is exactly the same as for creep tension tests. The alternation of applied stress is shown to have a very strong effect on the speed of diffusion.

- This work shows also that the observed type of coarsening in either $R_{\mathcal{E}}=0$ or $R_{\mathcal{E}}=-1$ fatigue can be explained using a recent coarsening model developed for superalloys deformed by creep.

\section{Acknowledgements:}

This work has been supported by the "CPR Stabilités Structurales des superalliages monocristallins" SNECMA and the CNRS. The as cast material were provided by SNECMA which is acknowledged for its interest in this work and for having performed all rupture tests in $R_{E}=0$ fatigue. The authors wish to thank Luc Rémy (Ecole des Mines-EvryFrance) for discussions and for providing us fatigue tests facilities.

\section{References:}

Ref.1: Gabb T.P., Miner R.V. \& Gayda J., Scripta Met. Vol. 20, pp. 513518,1986

Gabb T.P. \& Welsh G.E. Scripta Met. Vol.20 pp.1049-1054, 1986

Gabb T.P., Gayda J. \& Miner R.V. Met. Trans. A. Vol.17A, Part II, p497, Mars 1986

Ref.2: Milligan W.W., Jayaraman N. \& Bill R.C. Mat. Sci. \& Eng., 82 pp.127-139, 1986

Ref.3: Gabb T.P., Welsh G. \& Miner R.V., Scripta Met. Vol.21, pp.987992, 1987

Ref.4: Gabb T.P. \& Welsh G., Acta Met., pp.2507-2516, 1989

Ref.5: Gabb T.P., Welsh G., Miner R.V. \& Gayda J., Mat. Sci. \& Eng. , A108, pp189-202, 1989

Ref.6: Fritzmeier L.G. \& Tien J.K., $\Lambda$ cta Met., Vol. 36, N’2, pp. 283-290, 1988

Ref. 7: Chierragati R. \& Rémy L. Mat. Sci. \& Eng., A141, Part I pp1-9, Part II pp11-22, 1991

Ref.8: Fleury E., Thèse de Doctorat de l'Ecole Nationale Supérieure des Mines de Paris "Endommagement du superalliage monocristallin AM1 en fatigue isotherme et anisotherme" Octobre 1991

Ref. 9: Glatzel U. \& Feller-Kniepmeier M., Scripta Met. et Mat. , Vol.25, pp 1845-1850, 1991

Ref. 10: Hanriot F., Cailletaud G. et Rémy L. A.S.T.M. High temperature constitutive modelling-Theory and application, Book $\mathrm{N}^{\circ}$ H00667, 1991.

Ref.11: Buffière J.Y., Thèse de Doctorat de l'Institut National Polytechnique de Grenoble "Contribution à l'étude du comportement anisotrope d'un superalliage par essais de flexion", 1993

Ref.12: Fleury E. \& Rémy L. Mat. Sci. \& Eng., A167, pp 23-30, 1993

Ref.13: Décamps B., Brien V. and Morton A.J., Scripta Met, 1992

Ref.14: Royer PhD thesis of Grenoble 1995

Ref.15: Hirsh P.B., Howie A., Nicholson R.B., Pashley D.W, Whelan M.J., "Electron Microscopy of thin crystals" (New York Krieger), 1965 Ref.16: Bilby, Bullough and Smith 1955

Ref.17: Howie A. and Whelan M. J., Proc. R. Soc. A., 267,206, 1962

Ref.18: Fredholm A., Ayrault D., Strudel J.L, Colloque National

"Superalliages Monocristallins" Villard de Lans, 26-28 Feb. 1986 Ref.19: Benyoucef M., PhD thesis of Toulouse, 2 Feb 1994.

Ref.20: Mughrabi $\mathbf{H}_{\text {., }}$ Microscopics mechanisms of Metals Fatigue ICSMA5 Vol.3, p1636, 1979

Ref.21: Kuhn H.-A., Biermann H., Ungar T., Superalloys 1992, the Minerals, Metals, Materials Society, 1992

Ref.22: Mughrabi H., Biermann H. and UngarT, JMEPEG, Vol.2(4),pp557-564, 1992

Ref.23: Véron M., PhD thesis of INPG (Grenoble), 17 Jan.1995

Table II : Mechanical details of the repeated LCF tests

\begin{tabular}{|c|c|c|c|c|c|}
\hline$\Delta \varepsilon^{\text {tot. }}$ & Cycle & $\begin{array}{l}\text { Maximal } \\
\text { Stress in }\end{array}$ & $\begin{array}{c}\text { Maximal } \\
\text { Stress in } \\
\text { compression }\end{array}$ & $\begin{array}{c}\text { Plastic } \\
\text { deformation } \\
\text { per cycle }\end{array}$ & $\begin{array}{c}\text { Plastic } \\
\text { cumulated } \\
\text { deformation }\end{array}$ \\
\hline$\%$ & $\begin{array}{c}\text { Total number } \\
\text { of cycles }\end{array}$ & $\begin{array}{l}\sigma_{\text {tens }}^{\max } \\
\mathrm{MPa}\end{array}$ & $\begin{array}{c}\sigma_{\text {comp }}^{\max } \\
\mathrm{MPa}\end{array}$ & $\%$ & $\begin{array}{c}\% \\
(+/-) \\
\end{array}$ \\
\hline 0.63 & $\begin{array}{c}1 \\
\text { stabilized cycle } \\
200 \\
\end{array}$ & 458 & 9 & 0.01 & $\begin{array}{c}2 \\
(1)\end{array}$ \\
\hline 0.70 & $\begin{array}{c}1 \\
1 / 2 \text { lifetime } \\
5630\end{array}$ & $\begin{array}{l}608 \\
428\end{array}$ & $\begin{array}{c}- \\
178\end{array}$ & 0.04 & 200 \\
\hline 0.79 & $\begin{array}{c}1 \\
1 / 2 \text { lifetime } \\
17117 \\
\end{array}$ & $\begin{array}{l}663 \\
438\end{array}$ & - & 0.06 & 1027 \\
\hline 0.79 & $\begin{array}{c}1 \\
1 / 2 \text { lifetime } \\
21314\end{array}$ & $\begin{array}{l}642 \\
395\end{array}$ & 277 & 0.06 & 1279 \\
\hline 1.09 & $\begin{array}{c}1 \\
1 / 2 \text { lifetime } \\
3345\end{array}$ & $\begin{array}{l}815 \\
447\end{array}$ & 453 & 0.12 & 401 \\
\hline 1.27 & $\begin{array}{l}1 \\
1\end{array}$ & 739 & - & 0.153 & $\begin{array}{c}0.153 \\
(0.002)\end{array}$ \\
\hline 1.33 & $\begin{array}{c}1 \\
25\end{array}$ & $\begin{array}{l}661 \\
637 \\
\end{array}$ & $\begin{array}{l}143 \\
157 \\
\end{array}$ & 0.247 & $\begin{array}{c}0.47 \\
(0.06) \\
\end{array}$ \\
\hline 1.25 & $\begin{array}{c}1 \\
25\end{array}$ & $\begin{array}{l}732 \\
632\end{array}$ & $\begin{array}{l}57 \\
151\end{array}$ & 0.16 & $\begin{array}{c}2.10 \\
(0.46)\end{array}$ \\
\hline 1.26 & $\begin{array}{c}1 \\
1300 \\
\end{array}$ & $\begin{array}{l}759 \\
497 \\
\end{array}$ & $\begin{array}{c}47 \\
238 \\
\end{array}$ & - & $\begin{array}{c}\leq 125 \\
(15)\end{array}$ \\
\hline 1.28 & $\begin{array}{c}1 \\
2 \\
1300 \\
\end{array}$ & $\begin{array}{l}785 \\
764 \\
451 \\
\end{array}$ & $\begin{array}{c}50 \\
67 \\
357 \\
\end{array}$ & - & $\begin{array}{l}125 \\
(15)\end{array}$ \\
\hline 1.6 & $\begin{array}{c}1 \\
5 \\
25 \\
200 \\
\end{array}$ & $\begin{array}{l}704 \\
663 \\
611 \\
520 \\
\end{array}$ & $\begin{array}{c}39 \\
76 \\
123 \\
205 \\
\end{array}$ & 0.80 & $\begin{array}{c}160 \\
\text { (estimation) }\end{array}$ \\
\hline 1.6 & $\begin{array}{c}1 \\
5 \\
25 \\
\end{array}$ & $\begin{array}{l}707 \\
670 \\
620 \\
\end{array}$ & $\begin{array}{c}56 \\
81 \\
126 \\
\end{array}$ & 0.80 & $\begin{array}{c}20 \\
\text { (estimation) } \\
\end{array}$ \\
\hline 2.2 & $\begin{array}{c}1 \\
2 \\
3 \\
4 \\
5 \\
200\end{array}$ & $\begin{array}{l}975 \\
950 \\
930 \\
920 \\
910 \\
610\end{array}$ & $\begin{array}{c}85 \\
110 \\
126 \\
140 \\
150 \\
470\end{array}$ & 1.10 & $\begin{array}{c}100 \\
\text { (estimation) } \\
(33)\end{array}$ \\
\hline
\end{tabular}


Table III : Mechanical details of the alternate LCF tests

\begin{tabular}{|c|c|c|c|c|c|}
\hline $\begin{array}{c}\Delta \varepsilon^{\text {tot } / 2} \\
\% \\
\%\end{array}$ & $\begin{array}{c}\text { Cycle } \\
\text { Total number } \\
\text { of } \\
\text { cycles }\end{array}$ & $\begin{array}{l}\sigma_{\text {tens }}^{\text {max }} \\
M p a\end{array}$ & $\begin{array}{l}\sigma_{\text {com }}^{\max } \\
M p a\end{array}$ & $\begin{array}{c}\text { Plastic } \\
\text { deformation per } \\
\text { cycle } \\
\%\end{array}$ & $\begin{array}{l}\text { Total cumulated } \\
\text { plastic } \\
\text { deformation per } \\
\text { cycle } \\
\%\end{array}$ \\
\hline 1.26 & 1 & 932 & 952 & $\begin{array}{l}(+) 0.253 \\
(-) 0.449 \\
(+) 0.111 \\
\end{array}$ & 0.81 \\
\hline 1.26 & $\begin{array}{c}1 \\
\text { Stabilized } \\
113\end{array}$ & $\begin{array}{l}960 \\
874\end{array}$ & $\begin{array}{l}887 \\
887\end{array}$ & 0.77 & 80 to 90 \\
\hline
\end{tabular}

